\title{
Coverage Assessment for Community-Based Management of Acute Malnutrition In Rural and Urban Ghana: A Comparative Cross-Sectional Study
}

Joana Apenkwa

University of Education, Winneba

Samuel Kofi Amponsah ( $\nabla$ skamponsah001@st.ug.edu.gh )

Christian Health Association of Ghana, Accra

Newton K. Sam

Kwame Nkrumah University of Science and Technology (School of Public Health, KNUST

Reuben Osei-Antwi

Ghana Health Service

Emmanuel Nakua

Kwame Nkrumah University of Science and Technology (School of Public Health, KNUST

Anthony K. Edusei

Kwame Nkrumah University of Science and Technology (School of Public Health, KNUST

Easmon Otupiri

Kwame Nkrumah University of Science and Technology (School of Public Health, KNUST

\section{Research Article}

Keywords: Community-based Management of Acute Malnutrition, Point Coverage, Geographical Coverage, Ghana

Posted Date: February 2nd, 2022

DOI: https://doi.org/10.21203/rs.3.rs-43723/v3

License: (1) This work is licensed under a Creative Commons Attribution 4.0 International License. Read Full License 


\section{Abstract}

Background: Ghana for years has implemented the Community-based Management of Acute Malnutrition (CMAM) to reduce malnutrition in children. However, the prevalence of malnutrition remains high. This study aimed to determine CMAM coverage levels in the Ahafo Ano South (AAS), a rural district and Kumasi Subin sub-metropolis (KSSM), an urban district.

Methods: The study was a cross-sectional comparative study with a mixed-methods approach. In all, 497 mothers/caregivers and children under-five were surveyed using a quantitative approach while qualitative methods were used to study 25 service providers and 40 mothers/ caregivers who did not participate in the quantitative survey. Four types of coverage indicators were assessed: point coverage (defined as the number of Severe Acute Malnutrition cases [SAM] in treatment divided by total number of Severe Acute Malnutrition cases in the study district), geographical coverage (defined as total number of health facilities delivering treatment for SAM divided by total number of healthcare facilities in the study district), treatment coverage (defined as children with SAM receiving therapeutic care divided by total number of SAM children in the study district) and programme coverage (defined as number of SAM cases in the CMAM programme $\div$ Number of SAM cases that should be in the programme). The qualitative approach was used to support the assessment of the coverage indicators. Data were analyzed using STATA version 14 , and Atlas.ti, version 7.5 for the quantitative and qualitative data respectively.

Results: Geographically, only $6 \%$ of the facilities in the urban communities were participating in the CMAM programme as against $29 \%$ of rural district facilities. The districts had point coverage of $41 \%$ and $10 \%$ for the urban and rural districts respectively. The urban setting recorded a SAM prevalence of $52 \%$ as against $36 \%$ in the rural setting. The proportion of SAM children enrolled in CMAM was higher in KSSM as compared to AAS; $41 \%$ and $33 \%$ respectively. In both districts, the most likely factors to attract mothers/caregivers to utilize the CMAM services were: 'free services' and 'a cured child.' The qualitative approach showed that coverage improvement in both districts is hampered by distance, transportation cost, lack of trained personnel in the communities for community mobilization home visits and insufficient feeds.

Conclusion: To improve CMAM coverage, there is the need to train health workers to embark on aggressive health education strategies to encourage mothers/caregivers of malnourished children to utilize CMAM while ensuring that services reach those who need them.

Trial registration: This study is approved and registered with The Kwame Nkrumah University of Science and Technology Committee on Human Research, Ethics and Publications (CHRPE/AP/314/15). Participants were made to sign/thumb print to approve of their consent or otherwise to the study. Only participants who consented were involved in this study.

\section{Background}

Over the last two decades, the globe has recorded important reductions in under-five mortality. Nevertheless, some 5.3 million children under-five died in 2018 with the highest burden in sub-Saharan Africa (SSA). Nutrition-related factors account for nearly $45 \%$ of the global deaths [1], with the triple burden of 
malnutrition (undernutrition, hidden hunger and overweight/obesity), accounting for the two-in-five children under-five who are not growing well in West and Central Africa.[2] Globally, Severe Acute Malnutrition (SAM) is one of the most common causes of morbidity and mortality among children under-five, as it affects at least 19 million children[3] and accounts for $8.0 \%$ of annual child deaths worldwide.[4] A severely wasted child is nine times more likely to die than a child who is not wasted.[5] Developing countries account for $14.5 \%$ of the cases of malnutrition, and $45 \%$ of annual deaths stemming from malnutrition in children under-five years.[6] Additionally, in developing countries, about 100 million children are underweight and one-in-four are stunted.[6] Moreover, according to the United Nations Children's Fund (UNICEF), the World Health Organization (WHO) and the World Bank, approximately two thirds of all wasted children live in Asia, and almost one third in Africa.[7] In Ghana, according to the recent Demographic and Health Survey, among children under-five years, $19.0 \%$ were stunted, $5.0 \%$ were wasted, $11.0 \%$ were underweight and $4.0 \%$ were overweight.[8] The importance of addressing childhood malnutrition is a prerequisite for achieving internationally agreed goals, such as targets 2.2 and 3.2 of the Sustainable Development Goals (SDG) 2 and 3 respectively.

In order to curb the problem early at the community/household level, the Community-based Management of Acute Malnutrition (CMAM) concept was introduced as both a successful and a cost-effective approach for the management of uncomplicated severe acute malnutrition (SAM).[9] The CMAM intervention has proven to be very useful in many developing and under developed countries across the globe to avert soaring rates of malnutrition at the community level. However, inadequate human resources, especially Community Health Workers (CHWs), perception of caregivers that Ready-to-Use Therapeutic Foods (RUTFs) were being sold as a commodity, inadequate provision and unintended use of RUTFs, lack of antibiotics and inappropriate exit of children from the CMAM programmes have been some of the challenges to CMAM.[10] These factors militate against the original objectives for the introduction of CMAM, which are to help identify early signs of SAM, check for pedal edema, provide home visits, and refer to the out-patient therapeutic clinic.[11] CMAM encourages SAM cases without complications to access therapeutic foods and medications at the health facility for the mother/caregiver to administer the food at home, as part of the treatment model designed to avert the traditional long and expensive stay the health facility. The advantage here is that the whole family is involved and can also continue with their daily activities. This increases access and participation in the programme leading to higher coverage and better outcomes.[12] In addition, CMAM is both successful and a cost-effective way of allowing a wider coverage to the majority of children by engaging and mobilizing the community.[13] This approach is also effective with decreased chances of cross infections.[14]

Until recently, CMAM coverage assessments have been few. Even in the midst of paucity evidence, the review of assessment reports by Rogers et al. leaves much to be desired.[15] Between July 2012 and June 2013, they reviewed 44 coverage reports from 21 countries with emphasis on the treatment of SAM. Using context specific SPHERE standards, 38 out of the 44 assessments did not meet minimum standards. The average program coverage level of all 44 programs was $38.3 \%$. The contrasting results in coverage as projected compared with the assessment reports reveals the conceivability of certain barriers to the 
implementation of CMAM. These barriers, according to Rogers and colleagues, included the lack of awareness of malnutrition and the CMAM program among others.[15]

While national surveys such as the Ghana Demographic and Health Survey provide data on wasting and stunting, data on SAM are not available neither nationally nor sub-nationally. It is important to conduct assessments to ascertain the coverage level of CMAM within the Ghanaian setting to inform policy and programing.

\section{Methods}

\section{Participants and methods}

We conducted an analytical cross-sectional study with a mixed-methods approach - a combination of qualitative and quantitative data collection techniques - in an urban setting (Kumasi Subin submetropolis), and a rural setting (Ahafo Ano South district).

The Kumasi Subin sub-Metropolis (KSSM) is located in the Kumasi metropolis which is the second largest city in Ghana after the capital, Accra. KSSM is characterized by a good road network and social amenities. Additionally, the Komfo Anokye Teaching Hospital, tertiary level health facility, is within walking distance from the district centre. The Ahafo Ano South district (AAS) however, is characterized by poor road network, inadequate social amenities and is much poorer economically when compared with KSSM. AAS is about $30 \mathrm{~km}$ away from Kumasi.

The study adopted the Simplified Lot Quality Assurance Sampling Evaluation of Access and Coverage (SLEAC) method to sample communities for the study. A small sample size $(n \leq 40)$ is usually required to make an accurate and reliable classification. The SLEAC sampling method is a quick non-expensive method, which classifies coverage at the community level. The community could be a health center, a community-based Health Planning and Services (CHPS) compound or zone, a sub-district, a district, a region or a country, any clearly defined cluster. This method was adopted because it reaches a wider study area making the sample a true representation of the population under study.

With the SLEAC method, the health districts (Ahafo Ano South - AAS and Kumasi Subin sub-metropolis KSSM) were considered as sampling zones with a sample size of 40 communities each. The minimum number of communities to be sampled were calculated using the Spatially Stratified Sampling Method provided by the Coverage Monitoring Network (CMN).[16, 17]

In AAS, because there were no available maps for the area to show all the communities, the Spatially Stratified Sampling Method was used to select the study communities. All the names of the sub-districts together with their CHPS zones were listed, then all the communities under the zones were also listed. The grouping of the communities under the various zones ensured a spatially representative sample.[18] The sampling interval was then calculated by dividing the total number of communities by the sample size $(141 \div 40=3.525$ which was rounded up to 4$)$. A random number was generated with Excel (3) which served as the starting point for the counting and identification of sampled communities. The third community on 
the list was chosen as the starting point and the sampling interval was applied until the sample size of 40 was achieved. These calculations were not done for KSSM because the communities were not many. In all the 66 communities were included in the study sample. KSSM has 10 CHPS zones with 66 communities while AAS has 32 CHPS zones with 141 communities. So, mothers/caregivers and SAM/ children in a total of 106 communities were included: 40 in ASS (rural) and 66 in KSSM (urban).

For the quantitative survey, the study population comprised of mother/caregiver and malnourished child pairs who were resident in the two study districts while the study sample comprised the selected 497 mother/caregiver child pairs in the 106 communities from the two districts.

Three approaches - facility CMAM registers, snowballing and mopping up - were used to ensure that all the households (census) in the study communities were visited, and all children aged $6-59$ months were screened for their nutritional status with the aid of the United Nations Children's Fund (UNICEF) mid-upper arm circumference (MUAC) tape. The children were classified under either Severe Acute Malnutrition (SAM) cases or or not malnourished; only the mothers/caregivers of the SAM children were interviewed.

First, the names of mothers/caregivers captured in the community-based CMAM attendance register were followed up to their homes where they were invited to participate in the study if they consented and if any of the children aged $6-59$ months was assessed to have SAM. Second, a snow balling sampling approach was also used to reach mothers/caregivers whose children were malnourished. The snow balling was facilitated by the mothers/caregivers who had been identified in the CMAM register, followed up and interviewed. These mothers/caregivers directed the research team to another mother/caregiver until the last person was interviewed. Third, the rest of the households within the study communities, which had not been reached either through the register or through snow balling were identified through a mop up exercise and the children under-five in these households were assessed so that the mothers/caregivers with malnourished children were surveyed.

Eight enumerators were trained to use a structured questionnaire to survey mothers/caregivers of the 497 malnourished children identified in both districts (240 in KSSM and 257 in AAS). The respondents decided on a suitable time and place for the interviews. The interviews were conducted in English or Twi as preferred by the respondent; the interviews lasted up to 30 minutes. A data capture form was used to obtain additional data on coverage through a review of consulting room registers, Child Welfare Clinic (CWC) registers, monthly CWC reports, CMAM registers at the CMAM centres and the District Health Information Management System-2 (DHIMS-2).

For the qualitative survey, two populations were included - mother/caregiver and malnourished child pairs resident in the study districts and health workers in the two study districts. Qualitative interviews, in the form of knowledgeable informant interviews (KIIs) and focus group discussions (FGDs) were carried out among health service providers and mothers/caregivers respectively. The knowledgeable informants were purposefully selected due to their in-depth knowledge about the topic as healthcare service providers; one paediatrician one physician assistant, five nutritionists, 12 Community Health Officers/Nurses (CHOs/Ns) and six nurses all drawn from the two study sites. The KIls assessed the perceived coverage and barriers to 
coverage. These interviews, as well as the FGDs, investigated the acceptability, accessibility and availability of CMAM services. The mothers/caregivers who participated in the focus groups were not studied in the quantitative survey; they were invited to participate in the FGDs as they accessed services at the CMAM centers. The data collection period was from July, 2017 to January2018.

\section{Ethical approval}

was obtained from the Kwame Nkrumah University of Science and Technology, College of Health Sciences Committee on Human Research, Publication and Ethics (CHRPE/AP/314/15. Administrative approvals were sought from the Regional Health Directorate (urban setting)) and District Health Directorate (rural setting). Consent was equally sought from all participants who were involved in this study. Participants were made to sign or thumbprint to consent to participate, or otherwise after being briefed on the importance of the study. Only consented participants were involved in the study.

\section{Data analysis}

Quantitative data were double entered into a Microsoft Access 2007 database and validated after range and consistency checks were done. Data were cleaned and transferred to Stata 14.0 (Stata Corporation, Texas, and USA) for statistical analyses. Descriptive analyses were conducted to determine the frequencies of study variables of interest.

Coverage was computed as: point coverage, program coverage, treatment coverage and geographical coverage as follows:

1. Point coverage $=$ number of SAM cases in treatment $\div$ total number of SAM cases in the study district

2. Treatment coverage $=$ children with $S A M$ receiving therapeutic care $\div$ total number of $S A M$ children in the study districts.

3. Geographical coverage $=$ number of health facilities delivering treatment for $\mathrm{SAM} \div$ total number of healthcare facilities in the study district.

4. Programme coverage $=$ Number of SAM cases in the CMAM programme $\div$ Number of SAM cases that should be in the programme.

Mothers/caregivers with CMAM-related knowledge was determined from responses to a set of 10 questions that were equally weighted. A mark was awarded for each correct answer while 0 was awarded for each wrong answer; scoring five or lower points was deemed as low knowledge, while higher than five points was deemed as high knowledge. The 10 questions were administered only to mothers/caregivers who responded in the affirmative to the screening question whether they were currently (as at the time of the survey) utilizing the CMAM services.

A series of steps were followed during the qualitative data analysis; the process began by generating a priori, a list of organizing themes based on the study objectives. The coding of transcripts was guided by list of organizing themes (deductive) which was modified and expanded based on information derived from reading the transcripts (inductive). Two people coded all transcripts. After coding, a review of generated 
codes was done to ensure consistency in coding (constant comparison approach). The process continued with a more nuanced linkage of codes, this was done by the relationship between codes and the underlying meaning across codes. Representative quotes that best captured the idea was presented for illustration and the data analyzed with Atlas.ti, version 7.5 (Scientific Software Development GmbH, Berlin).

The Kwame Nkrumah University of Science and Technology Committee on Human Research, Ethics and Publications provided ethical clearance for the study (CHRPE/AP/314/15). Administrative clearance was also obtained from the Regional and District Health directorates. Verbal and written informed consents were obtained from the respondents and only those who consented were studied. All procedures and regulations spelt out by the ethical clearance Committee were duly followed.

\section{Results}

\section{Socio-demographic data}

While being a petty trader was the most common occupation in the urban setting (47.9\%), the mothers/caregivers in the rural setting were mostly farmers (64.6\%). Unemployment was marginally higher (14\%) in AAS than in KSSM (11.7\%). In both districts, the dominant ethnic group was Asante. Even though a higher proportion of the mothers/caregivers in AAS, when compared with KSSM, had education higher than middle school/junior high school (39.3\% versus 15.4\%), the mothers/caregivers in AAS were also more likely to have had an education lower than junior high school/middle school ( $25.4 \%$ versus $37.0 \%)$. The maternal modal age group in both settings was $20-35$ years.

The children under-five of the mothers/caregivers in the rural study site were more likely to be older than the children under-five in the urban study site; $89.9 \%$ of the children in ASS were at least one year old while in KSSM, $74.2 \%$ of the children were at least one year old. However, the mothers/caregivers in AAS were more likely to have had a higher number of children under-five years; only $49.8 \%$ of mothers/caregivers in AAS had less than two children under-five while $69.6 \%$ of their KSSM counterparts had less than two. (Table 1 ). 
Table 1

Socio-demographic characteristics of study sample

\begin{tabular}{|c|c|c|c|c|}
\hline & KSSM & & AAS & \\
\hline \multirow{2}{*}{$\begin{array}{l}\text { Characteristics of mother/caregiver and } \\
\text { index child }\end{array}$} & \multirow{2}{*}{$\begin{array}{l}\text { Frequency } \\
240\end{array}$} & Percentage & Frequency & Percentage \\
\hline & & 100 & 257 & 100 \\
\hline \multicolumn{5}{|l|}{ Mother/caregiver occupation } \\
\hline Artisan & 65 & 27.1 & 13 & 5.1 \\
\hline Farmer & 32 & 13.3 & 166 & 64.6 \\
\hline Trader & 115 & 47.9 & 41 & 16.0 \\
\hline Unemployed & 28 & 11.7 & 37 & 14.4 \\
\hline \multicolumn{5}{|l|}{ Mother/caregiver ethnicity } \\
\hline Asante & 144 & 60.0 & 142 & 55.3 \\
\hline Others & 96 & 40.0 & 115 & 44.7 \\
\hline \multicolumn{5}{|l|}{ Mother/caregiver education level } \\
\hline Below JHS/MSLC & 61 & 25.4 & 95 & 37.0 \\
\hline JHS/MSLC & 142 & 59.2 & 61 & 23.7 \\
\hline Above JHS/MSLS & 37 & 15.4 & 101 & 39.3 \\
\hline \multicolumn{5}{|l|}{ Mother/caregiver relationship with child } \\
\hline Caregiver & 16 & 6.7 & 102 & 39.7 \\
\hline Mother & 224 & 93.3 & 155 & 60.3 \\
\hline \multicolumn{5}{|l|}{ Mother/caregiver religion } \\
\hline Christian & 187 & 77.9 & 206 & 80.2 \\
\hline Islam & 53 & 22.1 & 51 & 19.8 \\
\hline \multicolumn{5}{|l|}{ Mother/caregiver age } \\
\hline$<20$ & 17 & 7.1 & 15 & 5.8 \\
\hline $20-35$ & 168 & 70.0 & 179 & 69.7 \\
\hline $36+$ & 55 & 22.9 & 63 & 24.5 \\
\hline \multicolumn{5}{|l|}{ Child age (months) } \\
\hline $0-11$ & 62 & 25.8 & 26 & 10.1 \\
\hline $12-23$ & 94 & 39.2 & 124 & 48.3 \\
\hline
\end{tabular}




\begin{tabular}{|lllll|}
\hline & KSSM & \multicolumn{3}{c|}{ AAS } \\
\hline $24-59$ & 84 & 35.0 & 107 & 41.6 \\
\hline Number of children alive & & & & \\
\hline 1 & 79 & 32.9 & 31 & 12.1 \\
\hline 2 & 63 & 26.3 & 49 & 19.1 \\
\hline 3 & 40 & 16.7 & 55 & 21.4 \\
\hline 4 & 27 & 11.3 & 51 & 19.8 \\
\hline 5 or more & 31 & 12.9 & 71 & 27.6 \\
\hline Number of children under-five & & & & \\
\hline Less than 2 & 167 & 69.6 & 128 & 49.8 \\
\hline Two or more & 73 & 30.4 & 129 & 50.2 \\
\hline
\end{tabular}

\section{CMAM Coverage}

Of the 497 malnourished children surveyed, 217 were SAM cases (125 in KSSM and 92 in AAS)); Only the SAM cases were used in the coverage indicator calculations. The urban district recorded a SAM prevalence of $52.1 \%$ while the rural recorded $35.8 \%$. Overall, the rural and the urban districts shared honors in terms of coverage indicators per the primary data from the field survey. The urban district had a point coverage of $40.9 \%$ compared with a very low figure of $9.8 \%$ for the rural district. Geographical coverage, probably the proxy indicator for all three coverage types, was low in both districts but was nearly five times higher in the rural district when compared with the urban setting; $29.0 \%$ versus $6.0 \%$. Programme coverage in the urban district (40.9\%) was nearly four times that recorded in AAS (9.8\%). However, in terms of treatment coverage, AAS fared better than KSSM 30.4 and 9.6 respectfully).

When secondary data for the study period (2016/2017) were retrieved from the District Health Information Management System (DHIMS-2) and computed for the same coverage indicators, we observed a different trend from what was seen in the primary data. Except for geographical coverage, the urban district had better coverage indicators. Point coverage in KSSM was 10 percentage points higher than in AAS; $80.9 \%$ versus $71.0 \%$. The secondary data figures for geographical coverage stayed the same as the primary data figures $-6.0 \%$ in KSSM and $29.0 \%$ in AAS. Treatment coverage was much higher in the urban district as compared to the rural site (73.0\% versus $6.0 \%)$. In general, when compared with the primary data, the secondary data provided higher coverage indicators in both districts. (Table 2) 
Table 2

CMAM coverage indicators

\begin{tabular}{|lllll|}
\hline $\begin{array}{l}\text { Indicators } \\
\text { (OPC data) }\end{array}$ & $\begin{array}{l}\text { KSSM } \\
\text { (DHIMS-2) }\end{array}$ & $\begin{array}{l}\text { KSSM } \\
\text { (FIELD DATA) }\end{array}$ & $\begin{array}{l}\text { AAS } \\
\text { (DHIMS-2) }\end{array}$ & $\begin{array}{l}\text { AAS } \\
\text { (FIELD DATA) }\end{array}$ \\
\hline Point coverage & $80.9 \%$ & $40.9 \%$ & $71.0 \%$ & $9.8 \%$ \\
\hline Treatment coverage & $73.0 \%$ & $9.6 \%$ & $6.0 \%$ & $30.4 \%$ \\
\hline Geographic coverage & $6.0 \%$ & $6.0 \%$ & $29.0 \%$ & $29 \%$ \\
\hline Programme coverage & $80.9 \%$ & $40.9 \%$ & $71.0 \%$ & $9.8 \%$ \\
\hline
\end{tabular}

A total of 105 women/caregivers in KSSM answered these questions while 132 did similar in AAS; the mothers/caregivers in KSSM were only slightly more knowledgeable when compared with those in AAS.

Enrollment of SAM cases (coverage) into the CMAM programme was generally low; of the 125 SAM cases in KSSM, only $40.8 \%$ had enrolled in CMAM while in AAS, $32.6 \%$ of the 92 cases were in the programme. We proceeded to further interview this sub-sample (51 out of 125, and 30 out of 92 for KSSM and AAS respectfully) on issues related to programme utilization as part of the coverage assessment. In both districts, the $\mathrm{CHO} / \mathrm{N}$ was most likely to have ensured the enrollment of the malnourished child. Only six children (three in each district), had enrolled more than once. While the vast majority (93.3\%) of the women in the rural setting treated their children with either home-prepared or industry-prepared therapeutic foods. The children in the urban setting's situation was different; - only $23.5 \%$ of these children received these foods. In both districts, there was a clear distancing away from resorting to faith-based treatment; only 3.3\% of the women in AAS had ever followed that path of treatment. Similarly, the women whose children were enrolled in CMAM, very rarely ever bought medications from the open market or consulted traditional healers. Even though health workers, such as $\mathrm{CHOs} / \mathrm{Ns}$, play a key role in the community-based components of the CMAM programme, the majority $(70 \%)$ of women in the urban communities did not have such health workers in their communities. The presence of a health worker in the community did not appear to have translated into frequent home visits and subsequently guidance on feeding practices.

Very few women were likely to have been visited more than once a month - none in AAS and $20 \%$ in KSSM (Table 3). 
Table 3

CMAM utilization

\begin{tabular}{|c|c|c|c|c|}
\hline \multirow[t]{4}{*}{ Variables } & \multicolumn{2}{|l|}{ KSSM } & \multicolumn{2}{|l|}{ AAS } \\
\hline & \multicolumn{2}{|c|}{ Coverage of CMAM } & \multicolumn{2}{|c|}{ Coverage of CMAM } \\
\hline & Frequency & Percentage & Frequency & Percentage \\
\hline & 51 & $(100 \%)$ & 30 & $(100 \%)$ \\
\hline How Child was Enrolled & 29 & 56.9 & 27 & 90.0 \\
\hline \multirow[t]{2}{*}{$\mathrm{CHN} / \mathrm{CHO}$} & 8 & 15.7 & 0 & 0.0 \\
\hline & 14 & 27.5 & 3 & 10.0 \\
\hline \multicolumn{5}{|l|}{ Parent } \\
\hline \multicolumn{5}{|l|}{ Prescriber } \\
\hline First Time Child was Enrolled & 48 & 94.1 & 27 & 90.0 \\
\hline Yes & 3 & 5.9 & 3 & 10.0 \\
\hline \multicolumn{5}{|l|}{ No } \\
\hline Number of Times & 3 & 100.0 & 2 & 66.7 \\
\hline Two & 0 & 0.0 & 1 & 33.3 \\
\hline \multicolumn{5}{|l|}{ Three } \\
\hline Why Child Discontinued & 2 & 66.7 & 1 & 33.3 \\
\hline Child not growing well & 1 & 33.3 & 2 & 66.7 \\
\hline \multicolumn{5}{|l|}{ Travelled } \\
\hline Treatment with Herbs & 0 & 0.0 & 8 & 26.7 \\
\hline Yes & 51 & 100.0 & 22 & 73.3 \\
\hline \multicolumn{5}{|l|}{ No } \\
\hline \multirow{2}{*}{$\begin{array}{l}\text { Treatment with home-prepared or industrially } \\
\text { prepared therapeutic foods }\end{array}$} & 12 & 23.5 & 28 & 93.3 \\
\hline & 39 & 76.5 & 2 & 6.7 \\
\hline No & & & & \\
\hline
\end{tabular}




\begin{tabular}{|c|c|c|c|c|}
\hline \multirow[t]{3}{*}{ Variables } & \multicolumn{2}{|l|}{ KSSM } & \multicolumn{2}{|l|}{ AAS } \\
\hline & \multicolumn{2}{|c|}{ Coverage of CMAM } & \multicolumn{2}{|c|}{ Coverage of CMAM } \\
\hline & $\begin{array}{l}\text { Frequency } \\
51\end{array}$ & $\begin{array}{l}\text { Percentage } \\
(100 \%)\end{array}$ & $\begin{array}{l}\text { Frequency } \\
30\end{array}$ & $\begin{array}{l}\text { Percentage } \\
(100 \%)\end{array}$ \\
\hline Ever resorted to faith-based treatment & 0 & 0.00 & 1 & 3.3 \\
\hline $\begin{array}{l}\text { Yes } \\
\text { No }\end{array}$ & 51 & 100.0 & 29 & 96.7 \\
\hline Ever purchased medication from open market & 1 & 2.0 & 1 & 3.3 \\
\hline Yes & 50 & 98.0 & 29 & 96.7 \\
\hline \multicolumn{5}{|l|}{ No } \\
\hline Ever purchased medication from pharmacy & 17 & 33.3 & 2 & 6.7 \\
\hline Yes & 34 & 66.7 & 28 & 93.3 \\
\hline \multicolumn{5}{|l|}{ No } \\
\hline Ever consulted traditional healer & 2 & 4.0 & 0 & 0.0 \\
\hline Yes & 49 & 96.0 & 30 & 100.0 \\
\hline \multicolumn{5}{|l|}{ No } \\
\hline Choice of treatment & 13 & 25.5 & 3 & 10.0 \\
\hline Father & 38 & 74.5 & 27 & 90.0 \\
\hline \multicolumn{5}{|l|}{ Myself } \\
\hline Health worker in the community & 15 & 30.0 & 25 & 83.3 \\
\hline Yes & 35 & 70.0 & 5 & 16.7 \\
\hline \multicolumn{5}{|l|}{ No } \\
\hline Number of health workers & 4 & 26.7 & 4 & 16.0 \\
\hline 1 & 7 & 46.7 & 21 & 84.0 \\
\hline 2 & 3 & 20.0 & 0 & 0.0 \\
\hline 3 & 1 & 6.7 & 0 & 0.0 \\
\hline \multicolumn{5}{|l|}{4} \\
\hline Regularity of house to house visits & 3 & 20.0 & 0 & 0.0 \\
\hline Twice weekly & 12 & 80.0 & 25 & 100.0 \\
\hline Monthly & & & & \\
\hline
\end{tabular}




\begin{tabular}{|c|c|c|c|c|}
\hline \multirow[t]{4}{*}{ Variables } & \multicolumn{2}{|l|}{ KSSM } & \multicolumn{2}{|l|}{ AAS } \\
\hline & \multicolumn{2}{|c|}{ Coverage of CMAM } & \multicolumn{2}{|c|}{ Coverage of CMAM } \\
\hline & Frequency & Percentage & Frequency & Percentage \\
\hline & 51 & $(100 \%)$ & 30 & $(100 \%)$ \\
\hline \multirow{2}{*}{$\begin{array}{l}\text { Health workers guide feeding practices at } \\
\text { home }\end{array}$} & 4 & 73.3 & 0 & 0.0 \\
\hline & 11 & 26.7 & 25 & 100.0 \\
\hline \multicolumn{5}{|l|}{ Yes } \\
\hline \multicolumn{5}{|l|}{ No } \\
\hline
\end{tabular}

During the FGDs and KIIs, coverage was also looked at in three aspects: acceptability, accessibility and availability of services. Focus group discussants opined that the CMAM programme did not go against their culture and so was acceptable to them.

"We accepted the program because it is part of the hospital services and not against our culture and religion that is why our husbands and leaders have not stopped us from coming here. Our people don't have problem with us using the hospital. "[Focus group discussion 1, KSSM] .

Some focus groups bemoaned geographical and financial challenges to accessing the CMAM services. Women in a focus group in the Ahafo Ano South district shared this view:

"We spend the little money on transportation to come here. We hardly can afford it. Coming all the way here also means not doing any productive work to earn the little proceeds we get from selling. There are many hospitals in the communities that I can walk to even when I don't have money for transportation." [Focus group discussion 4, AAS]

Service availability drew some strong comments in one of the focus groups in the rural district:

"Nutrition programme should be in all the hospitals/CHPS compound. We travel to the directorate sometimes on motor bike because there are no vehicles in our communities, only to come and meet supplies. Treatment should be effective, supportive and an encouragement. Also, the programme staff should be friendly and patient towards us." [Focus group discussion 3, AAS]

The knowledgeable informants in both districts suggested a positive attitude towards the CMAM programme. One knowledgeable informant mentioned that those who come to their facility were always happy with their services. She noted:

"Whether the barrier is money for transportation or lack of information, one cannot tell; but those who come here are mostly happy with us." [Pediatrician, Urban area] 
In the rural district, long distances and high costs of transportation to the CMAM centre for review and collection of RUTF, the lack of trained personnel in the communities for community mobilization and home visits, and, insufficient RUTF and other feeds were some factors limiting community access to the CMAM centre.

"Our district is located in a farming area so most mothers earn little to no income. They consume what they grow. Coming to the district capital is a big challenge to most of them because they do not have money for transportation, if the road is good. During rainy seasons, too some communities can only be reached through motor bike. Poor compliance especially during farming and rainy seasons are another challenge. Because we don't have community workers but CHNs and CHOs only, they do not practice home visits to complement our efforts" [Nutrition Officer 1, Rural area].

One respondent mentioned that not all mothers can access the programme because they live far from the facility and this brings a lot of financial strain on them.

"Hmmm... not every mother can access the programme. We have a challenge with accessibility because some mothers have to travel for some hours to reach the facility. Some mothers can't afford fare to and from the facility. So the facility is not that accessible to all the clients. [Nutrition Officer1, Urban area]

The CHNOs/Ns who work very closely with the mothers noted that most parents were poor and cannot commute to the CMAM centre weekly for their supplies amidst seasonal barriers such as rains and poor road network.

"Most of the parents (90\%) are poor and cannot afford to be commuting to the directorates weekly or twice a week for their supplies. In addition, seasonal barriers like rains, poor road networks, planting of crops and so on are barriers for the parents. Culture, religion and gender issues are not barriers to the people in our catchment areas'[CHO 4, rural area]

According to a knowledgeable informant the lack of an in-patient unit, a pediatrician and technical training on CMAM as well as sporadic shortages of RUTFs coupled with zero means of transport to follow up cases within the community, reduced service availability to the mothers/caregivers and the children who needed the services most. One respondent mentioned that within her facility, services were available in the inpatient care unit it run out of supplies, this she explained has led to referral cases for parents who could not afford to buy the foods. She noted this:

"We are always here for the in-patient service; we refer new cases to KATH when our wards are full or when the client cannot afford some of the services which is rare. The service is not available in the communities but everyone who comes here is attended to. Since we don't have enough community health workers, the parents who cannot come here are left out. [Pediatrician, Urban]

CHOs highlighted that inadequate staff for CHPS zones, the lack of staff training in CMAM and, lack of modern tools and equipment for the full implementation of CMAM as issues that affect the availability of the services within programme. One of them indicated this: 
"Our numbers are not adequate in the CHPs Zones/compounds. Most of us are the only health staff living in the compound so we cannot leave the compound for home visits. The government should pay allowances to the Community Health Workers so that they can help with the community visits and supervised feeding of the children. We, the staff should also be given allowances and more staff added to our numbers for community visits. Also, the directorates should be supplied with more Plumpy Nuts for easy distribution to prevent parents traveling long distance to get them. Most of the parents can walk to the CHPS compound for the feeds even when they do not have money for transportation." [CHO 5, Rural area]

"We also don't have volunteers anymore to take care of home visits because they demand money for their services and the money is not available." [PA, Rural area]

Some services are not available on a $24 / 7$ basis. A knowledgeable informant further explained that the inpatient unit is run throughout the week whereas the out-patient services are available only on specific days at specific times which is mostly Wednesdays. She stated this:

We run 24/7 for the inpatient unit but for the outpatients they are given specific times to visit the facility to get the service. The clinic days for the out-patient component is held on Wednesdays". [Nutrition Officer1, Urban area]

\section{Pull factors for CMAM utilization}

All mothers/caregivers in study sample were asked about the factors that would attract them to utilize the CMAM services. In both study sites, free service ( $98 \%$ urban versus $100 \%$ rural) and a cured child $(52.9 \%$ urban versus $83.3 \%$ rural), were the most likely factors of attraction to program utilization for the mothers/caregivers. The most unlikely pull factors in both sites were access and company; all the mothers in KSSM and $93.3 \%$ of the mothers in ASS were not attracted by difficult access to the service while the company of friends at the service sites served as a pull factor for only $3.9 \%$ and $6.7 \%$ mothers/caregivers in KSSM and AAS respectively.

More than half of the urban study sample was attracted by the following factors, to utilize CMAM services: programme staff attitude (54.9\%), RUTF availability (70.6\%), and access to Plumpy Nuts (54.9\%). On the other hand, the mothers/caregivers in AAS, had a wider variety of factors that attracted more than half of them to utilize CMAM services: funds for transport (83.3\%), partner's support (86.7\%), family support (76.7\%), CHW support (96.7\%), neighbors (80.0\%), treatment type (80.0\%), and treatment efficacy $(76.7 \%)$ as depicted in (Table 4). 
Table 4

Pull factors for CMAM utilization

\begin{tabular}{|lllll|}
\hline Variables & \multicolumn{2}{l}{ KSSM (n=240) } & \multicolumn{2}{l|}{ AAS (n=257) } \\
\cline { 2 - 5 } & \multicolumn{2}{l}{ Coverage of CMAM } & \multicolumn{2}{l|}{ Coverage of CMAM } \\
\cline { 2 - 5 } & Yes & No & Yes & No \\
\hline Attracted by Access & 0.0 & 100.0 & 6.7 & 93.3 \\
\hline Attracted by Funds for Transport & 12.2 & 87.8 & 83.3 & 16.7 \\
\hline Attracted by Availability of Transport & 17.7 & 82.3 & 30.0 & 70.0 \\
\hline Attracted by friends & 3.9 & 96.1 & 6.7 & 93.3 \\
\hline Attracted by partner's support & 35.3 & 64.7 & 86.7 & 13.3 \\
\hline Attracted by Family Support & 17.7 & 82.3 & 76.7 & 23.3 \\
\hline Attracted by CMAM Parents & 5.9 & 94.1 & 3.3 & 96.7 \\
\hline Attracted by CHW Support & 19.6 & 80.4 & 96.7 & 3.3 \\
\hline Attracted by Neighbours & 2.0 & 98.0 & 80.0 & 20.0 \\
\hline Attracted by community leaders & 13.7 & 86.3 & 23.3 & 76.7 \\
\hline Attracted by community appreciation & 19.6 & 80.4 & 30.0 & 70.0 \\
\hline Attracted by program staff & 54.9 & 45.1 & 30.0 & 70.0 \\
\hline Attracted by RUTF available & 70.6 & 29.4 & 3.3 & 96.7 \\
\hline Attracted by treatment type & 41.2 & 58.8 & 80.0 & 20.0 \\
\hline Attracted by free service & 98.0 & 2.0 & 100.0 & 0.0 \\
\hline Attracted by treatment efficacy & 51.0 & 49.0 & 76.7 & 23.3 \\
\hline Attracted by cured child & 52.9 & 47.1 & 83.3 & 16.7 \\
\hline Attracted by access to peanuts & 54.9 & 45.1 & 16.7 & 83.3 \\
\hline Attracted by other & 33.3 & 66.7 & 0.0 & 100.0 \\
\hline Multiple responses accepted & & & & \\
\hline
\end{tabular}

\section{Discussion}

Coverage in health programmes/services refers to the proportion of the targeted population that receives the services, utilizes the services, knows or practices a certain behaviour. The CMAM forum reported coverage as the proportion of the targeted population that receives the CMAM services. In this instance, it would be the proportion of SAM children who receive CMAM services. [18] 
Several CMAM assessments have reported very low programme coverage; in Sierra Leone of the 13 Ministry of Health Administrative districts that were assessed for CMAM coverage in 2012, not even one was deemed to have achieved high coverage $(>50 \%)$; more than $75 \%$ of the districts reported low coverage $(<20 \%)(18)$. Two surveys conducted in Ghana also reported low programme coverage of less than 30\% [19, 20]. Rodgers and others reviewed 44 coverage reports from 21 countries with an emphasis on treatment coverage, and arrived at an average of $38 \%$; low by any standard. Literature on the other coverage indicators such as point and treatment is scanty, but geographical coverage, which is more commonly reported in literature, could be a pointer to programme effectiveness; if geographical coverage is high, the services reached the targeted population, and it would be the first step to ensuring that all other coverage indicators are high and programme effectiveness is achieved.

We assessed various dimensions of CMAM coverage. To begin with, we used a quantitative survey to assess maternal utilization of CMAM services. Secondly, we used qualitative surveys to assess perceived coverage, challenges to coverage and maternal utilization of services. Finally, we computed point, treatment, geographic and program coverage indicators from primary and secondary data.

Based on secondary data from the DHIMS, the current study recorded much higher programme coverage levels in the two study districts than reported in other studies in Ghana; the programme coverage reported in two surveys conducted by the Ghana Health Service (GHS) in Ghana did not reach even half the levels reported in the current survey ( $<30 \%$ versus $81 \%$ ). Even though, the programme coverage captured through primary data collection in KSSM was similar to that of the GHS surveys of $2013(<30 \%$ versus $41 \%$ ), the figure for AAS captured via the same data collection means, was a third of the GHS level ( $<30 \%$ versus $10 \%$ ). These disparities are likely due to the denominator and numerator compositions; inaccuracies in case definitions and population data may account for this. If geographic coverage is used as proxy for measuring CMAM coverage in the two study districts then, the rural district will have a higher CMAM coverage.

The average treatment coverage levels reported from 21 countries by Rodgers and others is $38 \%$ [5], similar to the $30 \%$ reported in the current study using primary data from the rural area but much higher than the level in the urban area from the same data source. When compared with the levels obtained from the secondary data from the DHIMS, the results were checked; the differences here too may be due to misclassification errors.

The current study recorded the same levels of geographic coverage from both primary and secondary data; geographic coverage was nearly five times higher in the rural district when compared with the urban district. The absence of any discrepancy between the data sources is due to the fact that it is virtually impossible to make classification errors in neither the numerator nor the denominator for computing this coverage indicator.

Period coverage would have been an interesting indicator to capture but point coverage was preferred due to the paucity of data on the number of SAM recovered cases which was needed to calculate the period coverage; SAM recovered cases could have been MAM, and distinguishing between original MAM and SAM 
cases that had been MAM was not feasible. We did not come across any study that captured all the of forms of coverage levels assessed in the current study - point, treatment, geographic and program.

Even though the CMAM services were culturally acceptable to the women/caregivers, qualitative data showed that other factors ensured the women/caregivers did not utilize the services. Although some coverage indicators showed checkered results from primary and secondary data, geographical coverage was low from all data sources. The Myatt and Guerrero model (2013): 'A vicious coverage-effectiveness cycle,' tries to explain the nexus between low geographic coverage and poor outcomes/low effectiveness [23]. Low geographic coverage means that MAM and SAM cases get picked up only after they develop complications which would require long treatment with or without in-patient care with increased chances of defaulting because of additional costs. Such cases tend to lead to poor outcomes such as uninspiringly low recovery or even death. Poor outcomes whip up negative sentiments and discourage women from enrolling their children in the CMAM programme. In the current study, one of the most common pull factors for mothers/caregivers to utilize the CMAM services was a 'cured child;' half of the urban residents and 4-in-5 of the rural residents affirmed this. The 1978 Tanahashi model of health service coverage and effectiveness presents five levels of coverage; availability, accessibility, acceptability, contact and effectiveness, [21] all of which were covered in our assessment.

The SAM prevalence in our urban study district was $52 \%$ while the rural district recorded $36 \%$. Unfortunately, national surveys such as the Ghana Demographic and Health Survey and the Multiple Indicator Cluster Survey do not provide data on SAM. The data available in the routine health service data management system, the DHIMS, yield incredibly low national and sub-national SAM prevalence rates. The passive nature of this data management system leads to the capture of data on only in-patients (SAM admissions) and therefore uses very low figures as the numerator.

Maternal knowledge about child health interventions, including nutrition interventions, is expected to influence the level of utilization of the said intervention. Low knowledge of public health interventions is likely to affect coverage levels. The current study reports only a slightly higher level of knowledge among mothers in the urban district when compared with their rural counterparts. This may have been influenced by the slightly higher proportion of mothers/caregivers with a minimum of a junior high school level of education in KSSM. In the current study, the women/caregiver and SAM child pairs that had enrolled in CMAM was low in KSSM and very low in AAS. While all SAM cases in the rural district had been referred by the $\mathrm{CHN}$, a fourth of the cases in the urban setting were recognized by the mothers/caregivers themselves suggesting that with improved health education and intensive awareness promotion, the capacity of mothers, especially in the urban setting, could be increased to enhance CMAM coverage.

In Ghana, there are inequities between rural and urban populations in terms of coverage of health services; there are many more health facilities in urban than rural Ghana. With the exception of a few services such as family planning services, (this exception is a recent development), which has a greater coverage in rural than urban Ghana. [22] Other health services have higher coverage in urban than rural Ghana. Our study shows that the factors that act as pull factors in the utilization of CMAM services/health services (contact 
coverage) differ between urban and rural populations; the rural residents had a wider range of factors when compared with the urban population.

\section{Conclusion}

In conclusion, CMAM coverage in both study sites was low and this would translate into low programme effectiveness. In order to improve coverage, there is the need to train health workers to educate mothers/caregivers of malnourished children to utilize the services while ensuring that the services reach the doorsteps of households who need them.

There are limitations to this study. First, we are unable to determine period coverage from primary data. Second, the recall period for some of the issues was as long as 10 years, and respondents may have been unable to accurately recollect related events. Third, we acknowledge the inherent challenges cross-sectional surveys present in determining causal effect. Despite these challenges, this study is the first in Ghana to assess CMAM coverage in urban and rural settings using a mixed methods approach which presents the added advantage of triangulation. A wider. Range of coverage. Dimensions were assessed. The data allow us to draw some conclusions regarding the CMAM coverage in these two different settings as evidence to inform programing and policy to address coverage barriers.

\section{Abbreviations}

AAS

$\mathrm{CHN}$

$\mathrm{CHO}(\mathrm{s}) / \mathrm{N}(\mathrm{s})$

$\mathrm{CHO}$

CHW

CHPS

CMAM

CMN

CWC

DHIMS

FDG

KII

KSSM
Ahafo Ano South

Community Health Nurse

Community Health Officer (s)/ Nurse(s)

Community Health Officer

Community Health Worker

Community-based Health Planning and Services

Community Management of Acute Malnutrition

Coverage Monitoring Network

Child Welfare Clinic

District Health Information Management System

Focus Group Discussion

Knowledgeable Informant Interviews

Kumasi Subin-Sub Metro 


$\begin{array}{ll}\text { MAM } & \text { Moderate Acute Malnutrition } \\ \text { MUAC } & \text { Mid-upper Arm Circumference } \\ \text { RUTF(s) } & \text { Ready-To-Use Therapeutic Food(s) } \\ \text { SAM } & \text { Severe Acute Malnutrition } \\ \text { SDG(s) } & \text { Sustainable Development Goals } \\ \text { SLEAC } & \text { Simplified Lot Quality Assurance Sampling Evaluation of Access and Coverage } \\ & \\ \text { UNICEF } & \text { United Nation International Children's Emergency Fund } \\ \text { WHO } & \text { World Health Organization }\end{array}$

\section{Declarations}

\section{Ethics approval and consent to participate:}

The Kwame Nkrumah University of Science and Technology/Komfo Anokye Teaching Hospital Committee on Human Research, Publications and Ethicsapproved the study (CHRPE/AP/314/15). Administrative clearance was sought from the Regional Health Directorate and the Metropolitan/District Health Directorates as well as the Medical Directors of the study hospitals. Written and oral informed consents were obtained from study participants before any data were collected. The purpose of the study, benefits and risks (if any) were explained to study participants. Privacy and confidentiality were assured during all the data collection activities. All procedures and regulations under the ethical clearance were duly followed in order not breach any of the regulations governing the ethical clearance.

\section{Consent for Publication:}

Not Applicable

\section{Availability of data and Materials:}

The datasets used for the analysis of this study cannot be published openly due to sensitivity of the raw data. However, data is available upon request from the corresponding author.

\section{Competing Interests:}

None declared 


\section{Funding:}

This project did not received funding from any organization

\section{Authors Contribution:}

Joana Apenkwa conceived the idea of the work and was supervised by Professor Anthony Adusei and Professor Sam Newton. Data analysis was done by Samuel Kofi Amponsah, Emmanuel Nakua and Reuben Osei Antwi. Further proof reading and direction was given by Professor Easmon Otupiri. All authors critically provided feedback and helped organised the research, analysis and manuscript.

\section{Acknowledgements}

We are grateful to the health directorates of KSSM and AAS, the hospital management and the study participants for their support during the conduct of the study. We are equally grateful to the Coverage Monitoring Network for making their data collection tools and other resources available to the public for use.

\section{References}

1. United Nations Inter-agency Group for Child Mortality Estimation (UN IGME) (2019). 'Levels \& Trends in Child Mortality: Report 2019, Estimates developed by the United Nations Inter-agency Group for Child Mortality Estimation', United Nations Children's Fund, New York. https://www.unicef.org/reports/levelsand-trends-child-mortality-report-2019. Accessed March 15, 2020

2. The State of the World's Children 2019: Children, food and nutrition. UNICEF DATA. 2019 https://data.unicef.org/resources/state-of-the-worlds-children-2019/ Accessed May 10, 2020

3. Black RE, Victora CG, Walker SP, Bhutta ZA, Christian P, de Onis M, et al. Maternal and child under nutrition and overweight in low-income and middle-income countries. Lancet Lond Engl. 2013 Aug 3; 382(9890):427-51. DOl:https://doi.org/10.1016/S0140-6736(13)60937-X

4. Isanaka S, Langendorf C, Berthé F, Gnegne S, Li N, Ousmane N, et al. Routine Amoxicillin for Uncomplicated Severe Acute Malnutrition in Children. N Engl J Med. 2016 Feb 4; 374(5):444-53. doi: 10.1056/NEJMoa1507024.

5. Black RE, Allen LH, Bhutta ZA, Caulfield LE, de Onis M, Ezzati M, et al. Maternal and child under nutrition: global and regional exposures and health consequences. Lancet Lond Engl. 2008 Jan 19; 371(9608):243-60. doi:10.1016/S0140-6736(07)61690-0

6. WHO/WFP/SCN and UNICEF Joint Statement on Community-Based Management of Severe Acute Malnutrition UNICEF. https://www.unicef.org/publications/index_39468.html Accessed May 6, 2020.

7. UNICEF-WHO-The World Bank: Joint child malnutrition estimates - Levels and trends. WHO. World Health Organization; http://www.who.int/nutgrowthdb/estimates/en/ Accessed May 6, 2020.

8. Ghana Statistical Service (GSS), Ghana Health Service (GHS), National Public National Public Health Reference Laboratory (NPHRL). Ghana - Demographic and Health Survey 2014. CENTRAL DATA 
CATALOG / DHS / GHA_2014_DHS_V01_M. 2015

https://microdata.worldbank.org/index.php/catalog/2373 Accessed May 7, 2020

9. Saaka M, Wemakor A, Abizari A-R, Aryee P. How well do WHO complementary feeding indicators relate to nutritional status of children aged 6-23 months in rural Northern Ghana? BMC Public Health 5. doi https://doi.org/10.1186/s12889-015-2494-7

10. Tadesse E, Ekstrom E-C, Berhane Y. Challenges in Implementing the Integrated Community-Based Outpatient Therapeutic Program for Severely Malnourished Children in Rural Southern Ethiopia. Nutrients [Internet]. 2016 Apr 27;8(5). doi: 10.3390/nu8050251.

11. Blanarova L, Rogers E, Magen C, Woodhead S. Taking Severe Acute Malnutrition Treatment Back to the Community: Practical Experiences from Nutrition Coverage Surveys. Front Public Health. 2016; 4:198. eCollection 2016. doi: 10.3389/fpubh.2016.00198.

12. Bahwere P, Akor SA, Neequaye M, Sagoe-Moses I. Report on the Review of the Integration of Community-Based Management of Acute Malnutrition into the Ghana Health System, August/September 2010.: 50.

https://www.fantaproject.org/sites/default/files/resources/Ghana_CMAM_Review_Report_Oct2011.pdf Accessed May 11, 2020

13. UNICEF. Improving child nutrition: The achievable imperative for global progress - Institutional report. https://data.unicef.org/resources/improving-child-nutrition-the-achievable-imperative-for-globalprogress/\# Accessed 6th June, 2020

14. USAID's Bedaquiline Donation Program in Partnership with Johnson and Johnson | Archive - U.S. Agency for International Development. https://2012-2017.usaid.gov/what-we-do/globalhealth/tuberculosis/technical-areas/bedaquiline-donation-program Accessed 6th June, 2020

15. Rogers E, Myatt M, Woodhead S, Guerrero S, Alvarez JL. Coverage of Community-Based Management of Severe Acute Malnutrition Programmes in Twenty-One Countries, 2012-2013. PLOS ONE. 2015 Jun 4; 10(6):e0128666.

16. CMN. Stage 1: Selection of sample points. CMN. https://www.coverage-monitoring.org/sleac/stage-1selection-of-sample-points/ Accessed 5th June, 2020.

17. Guevarra, E., Guerrero, S., \& Myatt, M. Using SLEAC as a wide-average survey method. Field Exchange 42, January 2012. p39 Accessed June 5, 2020.

18. CMAM FORUM. CMAM Forum Update. Field Exchange 43 Gov Exp CMAM Scale Up. 2012 Jan 7; 64. https://www.ennonline.net/attachments/1616/FEX-43.pdf Accessed June 6, 2020

19. Ghana Health service. SLEAC/SQUEAC Coverage Survey Report - Agona West Municipal District. SAC/SQUEAC Coverage Survey Report. 2013a https://www.fantaproject.org/ Accessed June 6, 2020

20. Ghana Health Service SLEAC/ SQUEAT Coverage Report, (2013a). Ashaiman Municipal Assembly. SLEAC/SQUEAT coverage survey report. https//www.fantaproject, org/sites/default/files/resources/Coverage Survey Report-Ghana Ashaiman-2013_0.pdf Accessed June 7, 2020

21. Tanahashi T. Health service coverage and its evaluation. Bull World Health Organ. 1978; 56(2):295303.http://equityforchildren.org/wp-content/uploads/2013/10/Addl-Ref-4-bulletin_1978_562_295- 
303.pdf Accessed May 21, 2020

22. Ghana Statistical Service (GSS), Ghana Health Service (GHS), and ICF. Ghana - Maternal Health Survey 2017. https://microdata.worldbank.org/index.php/catalog/3186 Accessed May 15, 2020

23. Myatt $M$, Guerrero $S$. Why coverage is important: efficacy, effectiveness, coverage, and the impact of CMAM Interventions. Field Exchange 45. 2013 Jan 5; 39. https://www.ennonline.net/fex/45/coverage Accessed June 15, 2020 